\title{
Records in Contexts: the road of archives to semantic interoperability
}

\author{
Dunia Llanes-Padrón \\ Department of Information Science, University of Havana, Havana, Cuba \\ Juan-Antonio Pastor-Sánchez \\ Department of Information and Documentation, University of Murcia, Murcia, Spain
}

\begin{abstract}
Purpose - This paper examines the Records in Contexts proposal of a conceptual model (RiC-CM) from the International Council on Archives' (ICA) archival description and proposes an OWL ontology for its implementation in the semantic web.

Design/methodology/approach - The various elements of the model are studied and are related to earlier norms in order to understand their structure and the modeling of the ontology.

Findings - The analysis reveals the integrating nature of RiC-CM and the possibilities it offers for greater interoperability of data from archival descriptions. Two versions of an OWL ontology were developed to represent the conceptual model. The first makes a direct transposition of the conceptual model; the second optimizes the properties and relations in order to simplify the use and maintenance of the ontology.

Research limitations / implications - The proposed ontology will follow the considerations of the final version of the ICA's RiC-CM.

Practical implications - The analysis affords an understanding of the role of RiC-CM in publishing online archival datasets, while the ontology is an initial approach to the semantic web technologies involved.

Originality/value - The paper offers an overview of Records in Contexts with respect to the advantages in the field of semantic interoperability, and supposes the first proposal of an ontology based on the conceptual model.
\end{abstract}

Keywords Archival Description, Conceptual Description Models, Semantic Interoperability, Ontologies, Semantic Web, Records in Contexts

Paper type Conceptual paper

\section{Introduction}

The last 25 years have seen many changes to the process of archival description in terms of its conceptual, theoretical and methodological grounding. Internet-based technologies and users' new needs when accessing information have been the key factors behind this. User profiles have varied and this has led to new approaches on how to access and disseminate information generated and stored in archives. This is essential from both a technical and social perspective if society is to get closer to the ideal of an information democracy, transparent organizations and information reuse. Following these principles, today researchers and professionals alike are seeking to develop theoretical and technical solutions that facilitate the organization, description, search, retrieval and use of archival information on the Web.

The post-modern paradigm in the sphere of Information Sciences is having an influence on this transition toward new ways of representing information that are more in line with today's needs and approaches. The trend is toward creating schematic representations and formats that enable 
integrated access via the Web to all cultural and social heritages, including access to libraries, archives, museums and art galleries.

Semantic interoperability facilitates this since it goes beyond the use of formats for data exchange in digital contexts. The possibility of relating data from different spheres helps to break down the fences between the cultural institutions. It also affords an opportunity for these institutions to share information more efficiently and thus establish interconnections with information resources from other areas, e.g., economic, social and educational.

The preparation of an international conceptual model for archival description is a necessary step on the way to semantic interoperability. It opens up the way for the interrelation of open data in Archival Science. It also implies the appearance of new expectations of web use to disseminate and integrate archival data. In the past it was necessary to publish the description rules to establish the methodological and practical bases in order to then create the conceptual description models. These models, in turn, mark the course for the development of open formats, standard and ontologies for sharing all types of data.

The aim of this paper is to analyze the draft of the International Conceptual Model for Archival Description drawn up by International Council of Archives (ICA) and to provide an OWL ontology adaptation of it.

A study was made of the main standards and descriptive models published in Archival Sciences and of the purposes, entities and relationships of the ICA model. The entities, properties relationships of the conceptual model were optimized in order to prepare an OWL ontology proposal to represent Records in Contexts.

\section{Archival description in postmodern contexts: from rules to conceptual models.}

One consequence of the changes in Archival Sciences during the last decades of the twentieth century was a normalizing movement linked to the organization, description and management of information in digital archiving. The ICA and the International Organization for Standardization (ISO) are the two bodies responsible for drawing up and approving the standards regulating the scope and application of these processes and activities.

The ICA, in particular, was in charge of organizing the international process to regulate the description and retrieval of archival contents and establish the theoretical bases for the representation of information. The first result was the publication in 1992 of the Statement of Principles Regarding Archival Description (International Council on Archives [ICA], 1992), which set out the purposes of description for those times: to create uniform, relevant and explicit descriptions; to facilitate the retrieval and exchange of information about archival materials; to foster the exchange of authority data and the integration of descriptions made by different archives or institutions within an integrated information system (ICA, 1992).

Following this line, the ICA published four international norms which have had a direct impact on the archival communities in all countries. ISAD(G), ISAAR(CPF), ISDF and ISDIAH together 
standardized the data structures to be used at international level to describe records, producers, functions and institutions that safeguard archive records.

With the publication of this set of rules the Council sought to establish an internationally uniform description metadata structure and not an international contents structure. So each country had to draw up its own regulations for contents according to its own archival needs and demands. The following idea is outlined in ISAD(G): “This standard provides general guidance for the preparation of archival descriptions. It is to be used in conjunction with existing national standards regulations or as the basis for the development of other national standards.” (ICA, 2000, p.7).

This statement had an important effect on the development of national and regional regulations on data, content, presentation and encoding for describing records, producers and for the standardization of points of access. UK, USA, Canada, Portugal, Spain, Ireland, Brazil and Uruguay are the countries which have, to date, developed rules for the description process. In these countries, a set of standards were drawn up over a period of 20 years that afforded important and novel ideas on the standardization of archival description. Examples of these rules are:

- $\quad$ Rules for the Construction of Personal, Place and Corporate Names (RCPPCN)

- Manual of Archival Description (MAD3)

- Describing Archives: A Content Standards (DACS)

- Rules for Archival Description (RAD2)

- Orientações para a Descrição Arquivística (ODA)

- Norma Brasileira de Descrição Arquivística (NOBRADE)

- Manual de Descripción Multinivel (MDM)

- Norma Española de Descripción Archivística - Borrador (NEDA-I)

- Norma de Descripción Archivística de Cataluña (NODAC)

- Norma Gallega de Descripción Archivística (NOGADA)

- Norma Aragonesa para la Descripción de Autoridades (ARANOR)

- Norma para la Elaboración de Puntos de Acceso Normalizados de Nombres de Instituciones, Personas, Familias, Lugares y Materias en el Sistema de Descripción Archivística de los Archivos Estatales (NEPAN)

- Irish Guidelines for Archival Decription (IGAD)

- Norma Uruguaya de Descripción Archivística (NUDA)

- Encoded Archival Description (EAD)

- Encoded Archival Context-Corporate Bodies, Persons And Families (EAC-CPF).

Jointly with the development of these structures of data contents and encodings to regulate the representation of information in archives, there appeared the first conceptual models for archival description. The starting point of $\operatorname{ISAD}(\mathrm{G})$ was respect for collections, and from there arose a model that was conceived and focused solely for records. The one-dimensional principle based on multilevel description and the relations between the organizational levels of the records constitutes one of the most innovative proposals from the end of the last century. From this conception, the description of records should represent all the organization levels and link them hierarchically; from 
the general to the specific and, besides, providing information about the level that is being described and so avoiding repetition of data signaled in higher levels.

It is this hierarchical system in the description of records that makes it possible for a unified archival description which system can be interlinked and can link information from a single record to a series or to the collection of origin. The multilevel description principle eases the way towards today's single clip on a hyperlink allows one to browse the descriptions of a collection and the parts that make it up (Llanes Padrón, 2016, p. 41). This new principle closes the cycle of the creation of description tools (catalogs, indexes, guides and inventories) prepared separately and with no connection between them. Today, the core of the description is in the representation (activity) and not in the forms of manifestation (consultation tools).

The multilevel description model was designed to represent and interrelate the subtypes of the entity record, omitting other important aspects of the production, management and conservation of records (context). So, it is necessary to continue to rethink the principles of description and to move towards more complete conceptual models aimed at a description that includes other entities.

Now, when some archival communities are beginning to develop conceptual models of a national character, the model that has enjoyed the longest trajectory and the most attention is the Australian Government Recordkeeping Metadata Standard (AGRkMS), which has appeared in several versions: v. 2.0 (2008), v. 2.1 (2011) and v. 2.2 (2015). Another widely used model is the Specifications for the Electronic Recordkeeping Metadata Standard, published by the New Zealand Archives in 2008. Both are based on revisions of the Australian model, Recordkeeping Metadata Standard for Commonwealth Agencies, version 1.0 (2000).

The AGRkMS addresses a multidimensional model of archival description, thus distancing itself for the one-dimensional approach hitherto used. The model identifies five entities: record, agent, function, mandate and relation. The relation entity interrelates the other four entities to form a complete description (Gueguen et al., 2013, p. 165). For its part, the New Zealand model includes the same entities as defined in the Australian model.

Another conceptual model of huge scope and impact in the international archival community was drawn up in Spain by the Comisión de Normas Españolas de Descripción Archivística (CNEDA). One of the foremost proposals of this committee was to prepare a model which would identify the different types of entities, their relations and attributes and basic data requirements for the descriptions of records, agents and functions. This model recognizes the following entities: record, agent, function and their divisions, norm, concept, issue or event, and place. In 2012 the final version was published under the title: Modelo Conceptual de Descripción Archivística y Requisitos de Datos Básicos de las Descripciones de Documentos de Archivo, Agentes y Funciones (Conceptual Archival Description Model and Basic data requirements for the Descriptions of Archival Records, Agents and Functions).

In Finland, the National Archives (Arkistolaitos) appointed a working group to develop a conceptual description model. In 2013 the group published a draft version of the Finnish Conceptual Model for Archival Description. It advocates the separation and interrelation of the central description entities. It recognizes the entities: function, agent, manifestation, expression, 
item, information resources, life-cycle, mandate (norm), place, time and subject. The life-cycle is described associated to the management of records in business spheres (Gueguen et al., 2013, p. 12).

In 2012, the ICA formed the EGAD (Expert Group on Archival Description) with members from 12 countries, which succeeded the Committee for Good Practices and Standards, which until then had been responsible for normalization. This new group developed an international conceptual model for archival description and in September 2016 published a first draft of the Records in Contexts: A Conceptual Model for Archival Description (RiC-CM). Using the analysis of conceptual models developed in Australia, New Zealand, Spain and Finland, and the representation models published for libraries (FRBR) and museums (CIDOC-CRM), the EGAD prepared a model that respects the principles of archives and the needs of the archival community. The main aim of the RiC-CM is to complete and interrelate the four international description norms and to adapt to the new possibilities afforded by information and communication technologies to integrate data and services on the web.

The purpose of the archival conceptual models is to represent and interrelate all the entities involved in the descriptive process, and so create a multidimensional description of the objects from which information is extracted. Likewise, the fundamental premise of conceptual models is to facilitate interoperability between the information records of archives, libraries, museums and any other information system.

The Figure 1 gives a graphic representation of the history of the development of norms and models of archival description since the end of the 1980s.

The ICA set of standards and the other national and regional norms established the methodological and practical bases for the creation of conceptual description models. Records in Contexts: A Conceptual Model for Archival Description opens the way in archiving to the interrelation of open data and semantic interoperability in a web context. 


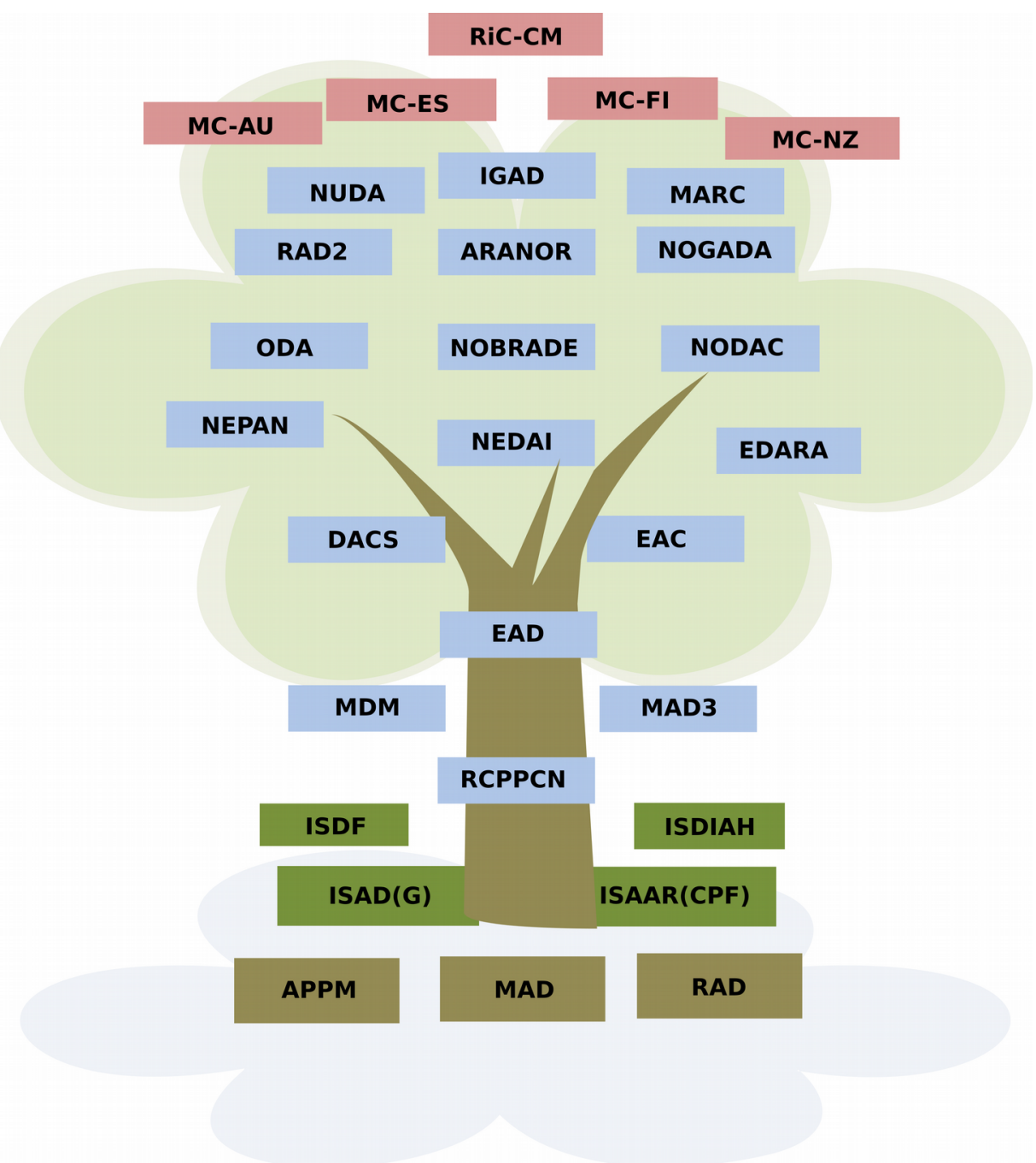

Figure 1. Evolution of norms and conceptual models for Archival Description. Source:Own

\section{Interoperability and reuse of archival descriptions in the semantic web context.}

Information systems are characterized by the heterogeneity of the platforms and information structures and the ensuing compatibility issues. Interoperability addresses various dimensions (Acar et al., 2009): organizational (collaboration between institutions), semantic (exchange of information), technical (interaction between systems) and temporal (preservation of digital information).

Semantic interoperability enables information systems to share data directly, with no access restrictions, data transformations or specific implementations (Sheth, 1999, p. 8; Hernández-Pérez et al., 2009, p. 68). Thus, there is an increased capability of metadata for description and information resource searches. The various technologies involved are developed along a pattern of layers of abstraction, guaranteeing backward compatibility over time and linking up to the principles of digital preservation (Day, 2003). 
Interoperability leads to information reuse as a requisite to access data, and takes into account quality, usefulness and licenses for use, contents, knowledge, products and services. Since the 1960s there has been a demand for data exchange between library catalogues and databases with records of documentary information. Some examples are the MARC format to exchange information linked to bibliographical records, or the Z39.50 protocol for the retrieval of unified information from different databases (Marcondes, 2016, p. 63).

However, the formats are a first step since they are associated to the syntactic interoperability. The semantic interoperability needs a greater capacity for abstraction and expressiveness to represent information. This is why conceptual models are the basis of the descriptive models to represent information objects according to certain attributes and the logical relations between them (Solodovnik, 2011, p. 5). They are a key component for interoperability since they allow bases to be established to harmonize data and processes with objectives that surpass the simple alignment and exchange of data (Tolk \& Muguira, 2003, p. 2).

The web offers a variety of technologies for accessing, publishing and sharing information following the principles of semantic interoperability to represent the meaning of the data. These technologies are grouped around the concept of semantic web based on IRIs for the unmistakable identification of information resources and descriptive vocabulary elements.

XML lies at the first level of interoperability, at the syntactic level to exchange and process data (Bray et al., 2008). However, there is also a need for a data model with a formal semantics to describe the properties and relations of the information resources. RDF does this structuring the descriptions through resource-property-value or resource-relation-resource triplets (Cyganiak et al., 2014). The descriptions of resources are grouped into RDF networks that are encoded in a machine readable form. Some of the formats to serialize RDF sentences are RDF/XML, N3/Turtle, JSON$\mathrm{LD}$ or RDFa. The RDF networks are grouped into datasets for downloading and processing in computer applications.

RDF provides some basic mechanisms to describe information objects. However, it is necessary to define and represent taxonomies of resources and attributes. With RDFS (Brickley \& Guha, 2014) it is possible to establish hierarchies of classes and subclasses of resources and to define new properties from existing ones. The description processes may require a high level of semantic formalization. Using OWL (Schneider, 2012), it is possible to define ontologies to model more complex aspects than those that can be expressed in RDFS.

Usually the RDF datasets can be downloaded in one of the formats mentioned. However, downloading an entire dataset is hardly an efficient procedure when wishing to search for and retrieve specific data. It should be noted that many of these complete datasets occupy several megabytes or even gigabytes. SPARQL allows consultations to retrieve RDF sentences that concord with a certain search pattern. These consultations are usually made via web services known as SPARQL Endpoints. It is also possible to retrieve data efficiently via open APIs that function using a series of well-documented consultation parameters.

Semantic web technologies can be used for the interoperability and reuse of data corresponding to archival descriptions. The use of RDF for publishing this type of data will enable greater 
interoperability than that offered only by formats like EAD o EAC. Adopting the RDF data model for the description of web resources gives a much higher degree of semantic expressiveness than any XML schema. The possibilities for reusing the data increase considerably when different distributions of a set of data are offered in various RDF serializations. Conceptual models like Records in Contexts can be modeled with RDFS and OWL to achieve semantic interoperability of archival datasets.

Semantic web technologies and Linked Open Data (LOD) based services offer a series of clear advantages for Archives (Baker et al., 2011; Sulé et al., 2016, p. 12; Moyano Collado, 2013, p. 7), while at the same time extending collaboration and exchange of data between GLAM (Galleries, Libraries, Archives and Museums) institutions. These organizations occupy a privileged position in the provision of reliable datasets, and also ensure their long term preservation. Data published as LOD are easy to consult, enlarge and reuse. Identifiers can be applied to descriptions of archival entities like records, agents, functions, places, subjects, etc. The reuse of controlled vocabularies (authorities, subject headings, classifications, thesauruses) allows for far more efficient descriptions of bibliographical and archival resources. The publication of datasets according to the Linked Open Data principles provides great potential for the reuse and conservation of cultural heritage in general and archives in particular (Hidalgo-Delgado et al., 2016, p. 147; McKenna, 2013, p. 352).

\section{The International Conceptual Model for Archival Description: Analysis and Trends.}

Archival description in current times, which many professionals refer to as post-modern or postcustodial times needs to consolidate its theoretical and practical bases starting from conceptual models. According to the Comisión de Normas Españolas de Descripción Archivística, a conceptual archival description model is "The representation of reality at a high level of abstraction at which the types of archival entities, their relations and attributes are all described.” (CNEDA, 2012, p. 19).

The most recent model to be published in this field is, in fact, the international conceptual model for archival description by the ICA: Records in Contexts. A Conceptual Model For Archival Description. As outlined earlier, this model was published by the EGAD in September 2016, and is considered to be still a draft, until its final approval following consultations with the international archival community.

The RiC-CM clearly lays out the essential purposes of archival description in today's post-modern contexts. The ICA puts forward three fundamental roles: Management of Records; Preservation of Records and Ongoing Use and Reuse of Records, (ICA, 2016, p. 14-15). As can be noted, the description is adapted to the new times, where the representation of archival information is a determinant factor for its management, digital preservation and reuse and semantic interoperability of data on the web.

The definition of descriptive metadata in records management systems ensures an exact representation of the context, the contents and the structure of the records, which in turn ensures short, medium and long term management (International Standards Office [ISO], 2016, p. 8). Thus, 
representing the functions, occupations, activities and transactions that give rise to the records is of vital importance for the ongoing use of records. By including this purpose in the model, the ICA is recognizing that description is not a task for historical archives alone, but that it is an important process for the integrated management of information and knowledge.

According to the RiC-CM, description also guarantees the preservation of archival information in digital contexts. Describing the entities makes maintaining authenticity and veracity of records viable; through the act of describing the context in which the records were created, accumulated and maintained is preserved. Recording the context by describing it is essential for the preservation of records (ICA, 2016, p. 15). In today's times, preservation strategies focus on safeguarding and maintaining packages of metadata, and it is important to highlight that descriptive metadata (content, context and structure) are determining factors for the preservation of a world memory.

Finally, the international model outlines the importance of description for the reuse of archival data in web environments. The concept of reuse is linked to the implementation of conceptual models and data structures (properties or attributes); so the international model of description is positioning the bases for archives to benefit from the technological advantages of the semantic web with regard to interoperability, data reuse and LOD based services.

On this issue the RiC-CM states:

The description created to facilitate management and preservation also serves those interested in records as witnesses to life and work activities, to people, to human-made and natural events, to things made, things studied, things done, and more. Anything and everything may be the subject of records. For people who want to use records as evidence for scholarly, business, personal, or other purposes, description facilitates discovering, locating, identifying, retrieving, evaluating, and understanding them. Such ongoing use and reuse of the records becomes part of the history of the records; it re-contextualizes them. The use and reuse generate other records, thereby extending the social-document network. (ICA, 2016, p. 7).

The international model also establishes which entities will be represented and interrelated in the archival information systems. For the CNEDA, an entity is "Any real or abstract object that exists, has existed, or may exist.” (CNEDA, 2012, p. 18). The description entities defined in the RiC-CM are:

- RiC-E1: Record

- RiC-E2: Record Component

- RiC-E3: Record Set

- RiC-E4: Agent

- RiC-E5: Occupation

- RiC-E6: Position

Dunia Llanes-Padrón, Juan-Antonio Pastor-Sánchez, (2017) "Records in contexts: the road of archives to semantic interoperability", Program, Vol. 51 Issue: 4, pp.387-405, https://doi.org/10.1108/PROG-03-2017-0021 
- RiC-E7: Function

- RiC-E8: Function (Abstract)

- RiC-E9: Activity

- RiC-E10: Mandate

- RiC-E11: Documentary Form

- RiC-E12: Date

- $\quad$ RiC-E13: Place

- RiC-E14: Concept/Thing

This group of entities constitutes the archival objects that will be described and related in the integrated information systems. On the basis of its four standards, the FRBR, the CIDOC-CRM and the models from Australia, New Zealand, Spain and Finland, the ICA proposed a set of entities that represent the reality of archival description and, thus, an international consensus has been reached. The model envisages the entities defined in the international norms: Record (ISAD(G)), Agent (ISAAR(CPF)-ISDIAH) and functions and activities (ISDF).

The entities record, agent, function, mandate, place, period, concept or subject are common denominators in the conceptual models developed in Information Sciences. Hence, this international description model underlines the idea of creating an integral semantic model that facilitates representation, relation and interoperability of the contents of all information institutions in the web context and supported by ontological developments.

Nevertheless, the RiC does not include entities like manifestation, expression, item, collection, object that were defined in the Finnish Conceptual Archival Model, in group 1 of the FRBR or in the CIDOC-CRM, which shows that it is also possible to establish differentiations in the descriptive schemas without hindering the compatibility and interoperability that must exist between information systems.

The model gives a lot of importance to the production of records and it makes this explicit not only in the purposes but also in the definition of entities. The entities function, abstract function, occupation, activity, position or mandate are determinants for defining the contest of the creation of records and so guarantee the veracity, integrity and authenticity of the archival documents. Besides, it defines entities like date, place, concept or subject that are essential for creating normalized points of access which are determining in the search and retrieval of information process.

In this document the subtypes of these entities are not presented directly; it is explained that each of the entities will be treated as different types and must be described differently, even though many of the properties will be shared. In the RiC the approach is for a separation of the main components of the description even if they are interrelated, since a differentiated treatment of the records, for example, will better reflect its context and the purpose for which it was created. 
In ISAD $(G)$ and the other published national norms published, entity subtypes are defined for record, agent, function, norms or relations. The concept of description level is not envisaged in this new model where hierarchy is not a determining factor; instead it is the unique representations based on exact relations between independent entities that are able to capture dissimilar and complex creation contexts. Description in the RiC-CM is presented in a net form and not as a hierarchical model, so allowing the description of individual collections while assuming the representation of the various layers of contexts that exist between these collections and others. This multidimensional schema presents the description of records and record sets, their interrelations with other entities (agents, functions, activities, norms). The $\mathrm{RiC}$ recognizes Respect for Collections while also allowing work with record sets from complex origins (ICA, 2016, p. 10).

A detailed analysis of the model shows that although subtypes are not defined for entities like record sets, agents, functions, occupations, activities, mandates or place, they are categorized in the definition of properties. Using the RiC-P Type the typology or sub-type of each is defined. For example, the RiC-P23 Type for Record Sets is defined as: collection, section, series, file, collection, project, among others; the RiC-P32 Type for agent is defined and exemplified as: individuals, groups, families, institutions, conferences, delegate agents and unknown authority; the RiC-P55 Type for mandate is defined as: decree, legislation, rule, letter of appointment as well as other entities such as occupation, position, function, activity or documentary form. This shows that the model does not totally rule out hierarchical descriptions even though it defends a description based on the fabric of the related entities.

Relations are another determining aspect in a conceptual model. A relation is an association of any type that is established with an entity defined in the model. Defining the types of relations accurately and broadly guarantees a later increased search capacity of the systems as well as the retrieval and use of information. There are 792 relations established in the RiC-CM, a number that may grow when the final version of the model is published.

The definition of various types of relations between entities means more information can be interrelate, which facilitates the reuse of interrelated data. Several authors consider that the key to the semantics between information resource contents lies in the interrelating these (Sheth et al., 2004, p. 65), and, hence, the importance of establishing a broad set of relations in the models and later use encoding schema to make them inter-computer readable. The Figure 2 shows an example of archival description according to the relations and entities defined in the RiC-CM and later, in the text, there is an example of its RDF encoding RDF in Table 5. 


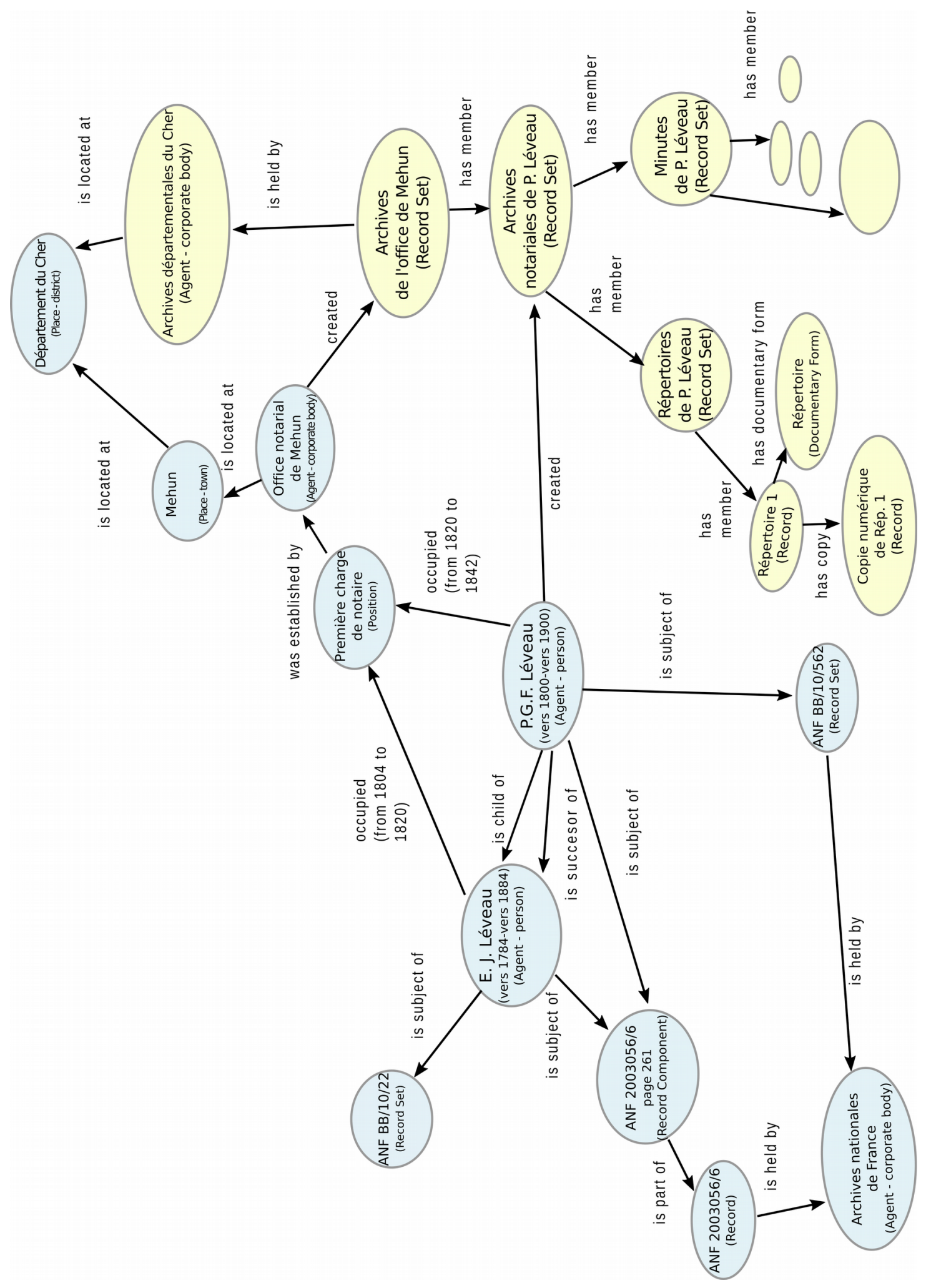

Figure 2. Example of archival description from the RiC-CM. Source: ICA, 2016, p. 93

Archival description from RiC-CM facilitates consultation of heterogeneous resources which are

Dunia Llanes-Padrón, Juan-Antonio Pastor-Sánchez, (2017) "Records in contexts: the road of archives to semantic interoperability", Program, Vol. 51 Issue: 4, pp.387-405, https://doi.org/10.1108/PROG-03-2017-0021 
interlinked from a central hub provided by the model and as a result allows the discovery and sharing of more information in a net modeling. The relations in this example appear in a single direction, but they can be in inverse directions. This conceptual model places the archives on the way toward decentralized semantic interoperability and not founded on the exchange of metadata schemas. The development of an ontology of this model, based on the Resource Description Framework (RDF), is the next step in positioning the archival resources in the dynamics of direct publication on the web, the Linked Open Data, the reuse of data and interoperability between information systems.

\section{Proposal of an Ontology for the Conceptual Archival Description Model}

Ontologies offer a huge capacity of semantic interoperability, enabling complex descriptions of objects and of the logical relations between them (Obrst, 2003). An OWL ontology allows a certain knowledge domain to be represented by organizing resources that are identified with IRIs according to a class taxonomy. Each class has data properties and object properties. The data properties allow the description of certain characteristics using textual values, numeric values, dates, etc. Elsewhere, object properties allow relations between resources to be established. Using OWL, it is possible to define the ranges and domains of the properties with great precision and to establish certain cardinality constraints.

The definition of OWL ontologies from conceptual models has been widely proposed for FRBR (Ciccarese \& Peroni, 2011; Shotton \& Peroni, 2016), RDA (Hillmann et al., 2010) and CIDOCCRM (Reinhardt, 2009). The EGAD is developing an OWL ontology called RiC-O for implementation of RiC-CM model in order to publish archival data on the web. RiC-O is not available yet but it is possible to put forward some features of its modeling from an analysis if the RiC-CM. The level of detail of the conceptual model allows for a practically direct implementation towards an OWL ontology. However, there are some features of the model that need to be considered to achieve a more efficient ontology than that obtained through mere transposition.

The RiC-CM modeling starts from a well-defined domain that is to be represented. However, the pragmatics of an ontology determine certain aspects of its modeling so that its use, maintenance and integration with other ontologies or data vocabularies can be done simply. Thus, the proposal presented here addresses certain aspects that may improve the official version (or later updates) of RiC-O. The ontology proposed here is based on a draft of the conceptual model and its intention is to discuss the implementation of Records in Contexts into an OWL ontology. For this reason, in the future it must be adapted to the changes that can be introduced in the final version of Records in Contexts.

The namespace http://purl.org/ica/ric has been added in PURL and can be used to download the ontology. The prefix "ric" is used to refer to the namespace of the ontology. The documentation is available at http://skos.um.es/TR/ric/ 


\subsection{Taxonomy of the classes}

RiC-CM identifies 14 entities to refer to the main description elements. The ontology models these entities of the conceptual model as OWL classes on which the corresponding data properties and object properties are defined. The draft of the RiC-CM specializes in the "RiC-E4 Agent" entity and defines the relations (ICA, 2016, p. 30-90). Thus, three specific subtypes are identified for the "RiC-E4 Agent" (delegate agents, groups and individuals) represented with their corresponding subclasses. Taking into account these considerations the Table 1 shows a proposal for the class taxonomy for the ontology.

\begin{tabular}{|l|l|l|}
\hline RiC Entity & Denomination & OWL class \\
\hline RiC-E1 & Record & ric:RiC-E1-Record \\
\hline RiC-E2 & Record Component & ric:RiC-E2-Record Component \\
\hline RiC-E3 & Record Set & ric:RiC-E3-Record Set \\
\hline \multirow{2}{*}{ RiC-E4 } & Agent & ric:RiC-E4-Agent \\
\cline { 2 - 3 } & Delegate Agent (subtipo de Agent) & ric:RiC-E4-Agent-DelegateAgent \\
\cline { 2 - 3 } & Person (subtipo de Agent) & ric:RiC-E4-Agent-Person \\
\cline { 2 - 3 } & Group (subtipo de Agent) & ric:RiC-E4-Agent-Group \\
\hline RiC-E5 & Occupation & ric:RiC-E5-Occupation \\
\hline RiC-E6 & Position & ric:RiC-E6-Position \\
\hline RiC-E7 & Function & ric:RiC-E7-Function \\
\hline RiC-E8 & Function (Abstract) & ric:RiC-E8-FunctionAbstract \\
\hline RiC-E9 & Activity & ric:RiC-E9-Activity \\
\hline RiC-E10 & Mandate & ric:RiC-E10-Mandate \\
\hline RiC-E11 & Documentary Form & ric:RiC-E11-DocumentaryForm \\
\hline RiC-E12 & Date & ric:RiC-E12-Date \\
\hline RiC-E13 & Place & ric:RiC-E13-Place \\
\hline RiC-E14 & Concept/Thing & ric:RiC-E14-ConceptThing \\
\hline
\end{tabular}

Table 1. Modeling of OWL classes from the RiC-CM entities. Source: own.

OWL allows new subclasses to be defined from the proposals such that the semantic interoperability of the datasets that use the ontology is guaranteed together with extensibility and flexibility of application. The property "RiC-P32 Type" allows us to define more specific types for the subclasses that represent individuals, groups and delegate agents (ric:RiC-P32-type in the proposed ontology) . 


\subsection{Modeling of properties.}

The conceptual model proposed by the EGAD defines properties to describe data about the entities. There are several properties (from the RiC-P1 to the RiC-P4) whose application domains run to all the entities of the model. The remaining properties are defined for specific entities.

Some of the specific properties defined for different entities have a similar, even identical, semantics. In these cases they can be modeled in the ontology as a single property whose domain would be the union of the corresponding classes. Let us take as an example the properties of the conceptual models "RiC-P11 Language Information" and "RiC-P34 Language Information”. Their purpose and semantics are the same but the draft of the conceptual model defines them as different properties. It would be more convenient were the ontology to define a single property, ric:Ric-PlanguageInformation, whose domain would be the union of the classes corresponding to the entities "RiC-E1-Record", "RiC-E3-RecordSet" and "RiC-E4-Agent". Another example is the properties to represent information about the history of entities (RiC-P20, RiC-P28, RiC-P35, RiCP44, RiC-P47, RiC-P50, RiC-P54, RiC-P57, RiC-P60), which have been modeled using the property ric:RiC-P-history

In other cases, the semantics are not identical but very similar, since the aim is to describe a same type of characteristic for different entities. This happens with the "Type" properties, present in various entities [1]. Clearly, in these cases the semantics are not exactly the same since the domain of these properties varies according to the entities in which they can be applied. However, the semantics of these properties do have a common objective: to categorize a resource within a classification or list of types that is specific to each entity. From the perspective of representing the domain of the ontology, the proposal presented here considers the semantics of these properties to be the same. Thus, a single property ric:RiC-P-type is defined, so establishing the domain of the property as the union of the classes corresponding to the entities involved, as the Table 2 shows.

\begin{tabular}{|l|c|}
\hline 1 & ric:RiC-P-type rdf:type owl:ObjectProperty \\
2 & rdfs:domain [ rdf:type owl:Class ; \\
3 & owl:unionof ( ric:RiC-E10-Mandate \\
4 & ric:RiC-E11-DocumentaryForm \\
5 & ric:RiC-E12-Date \\
6 & ric:RiC-E13-Place \\
7 & ric:RiC-E14-ConceptThing \\
8 & ric:RiC-E3-RecordSet \\
9 & ric:RiC-E4-Agent \\
10 & ric:RiC-E5-Occupation \\
11 & ric:RiC-E6-Position \\
12 & ric:RiC-E7-Function \\
13 & ric:RiC-E9-Activity) \\
14 & ]
\end{tabular}

Table 2. Definition of the domain of the property ric:RiC-P-type. Source: Own. 
The values of the different properties are represented using RDF literals (rdfs:Literal). This offers greater flexibility in representing all types of values: strings, numbers, dates, etc. Nevertheless, the RiC-CM conceptual model indicates that the range of some properties can be obtained from the terms of a controlled vocabulary. This means that these properties store the text of those terms or can refer to IRIs from other resources. These properties had been defined simultaneously as owl:ObjectProperty and owl:DatatypeProperty because there is not any OWL axiom that define these classes as pairwise disjoint. Therefore, the properties defined in this way, can store the text of the terms and the references of resources (e.g., SKOS concepts).

Using these modeling decisions to represent 69 properties, 38 data properties and 2 annotation properties have been defined. Additionally, 15 object properties were defined to represent potential relations with controlled terms.

\subsection{Modeling of relations.}

The RiC-CM draft defines 792 relations to link entities. This increases the complexity of the use and maintenance of the ontology. Many of these relations have similar (even identical) semantics, so in OWL they can be defined as a single object property. This is exemplified with the relation "is member of" which is used with entities that represent records, record sets and agents ("RiC-E1 Record”, "RiC-E3 Record Set” and "RiC-E4 Agent” respectively). According to the draft, three relations are defined as reflected in the Table 3.

\begin{tabular}{|l|l|l|l|}
\hline Number of relation & Name & Domain & Range \\
\hline RiC-R18 & is member of & RiC-E1 Record & RiC-E3 Record Set \\
\hline RiC-R143 & is member of & RiC-E3 Record Set & RiC-E3 Record Set \\
\hline RiC-R266 & is member of & RiC-E4 Agent & RiC-E4 Agent (of type group) \\
\hline
\end{tabular}

Table 3. Relations “is member of” of RiC-CM. Source: Own, based on ICA, 2016.

With this relation, the records can only be linked to record sets, these record sets to other record sets and the agents with other agents of type group.

For the previous example, the proposed ontology defines a single object property ric:RiC-R-isMemberof whose domain would be the union of the classes ric:RiC-E1-Record, ric:RiC-E3-RecordSet y ric:RiC-E4-Agent. However, it is not sufficient to define just a single property, since the range of relations varies according to the classes on which they are defined. To unify these types of relations using OWL, it is necessary to establish definitions that constrain the use of a property. To constrain the use of this property in the class ric:RiC-E1-Record solely to the resources in the class ric:RiC-E3-RecordSet the corresponding OWL definition within the Table 4 would be established. 


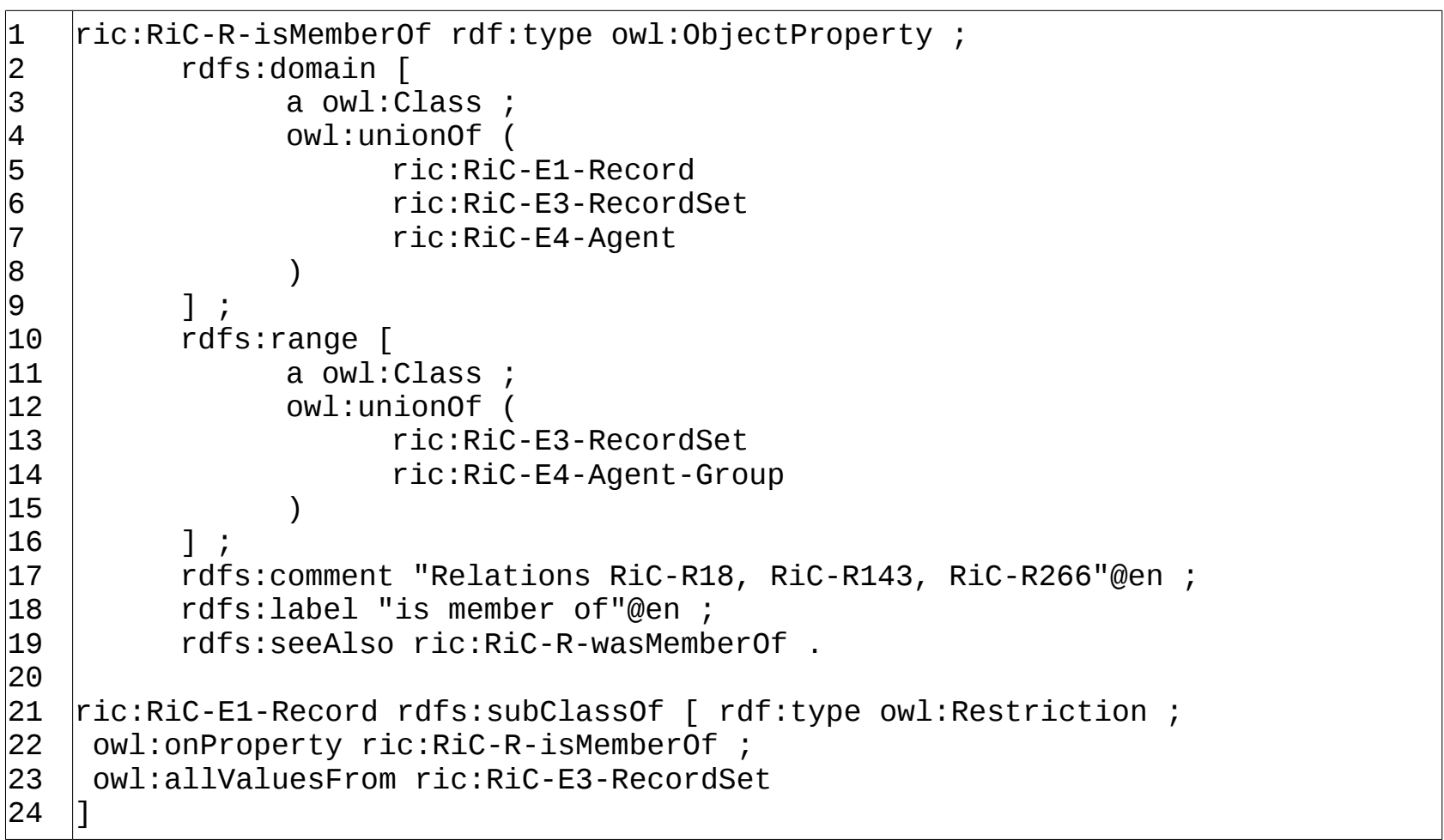

Table 4. Modeling of the relations "is member of" with the definition of the constraint of the property ric:RiC-R-is Member Of on the class RiC-E1-Record. Source: Own.

Thus, in the proposed ontology the 792 relations of the draft conceptual model are defined through 166 object properties. These also include the definitions of the corresponding inverse, reflexive and transitive properties.

Below, the Table 5 includes the RDF encoding of Figure 2 using the N3/Turtle format. The prefix "ex" refers to the namespace of the resources intervening in the example.

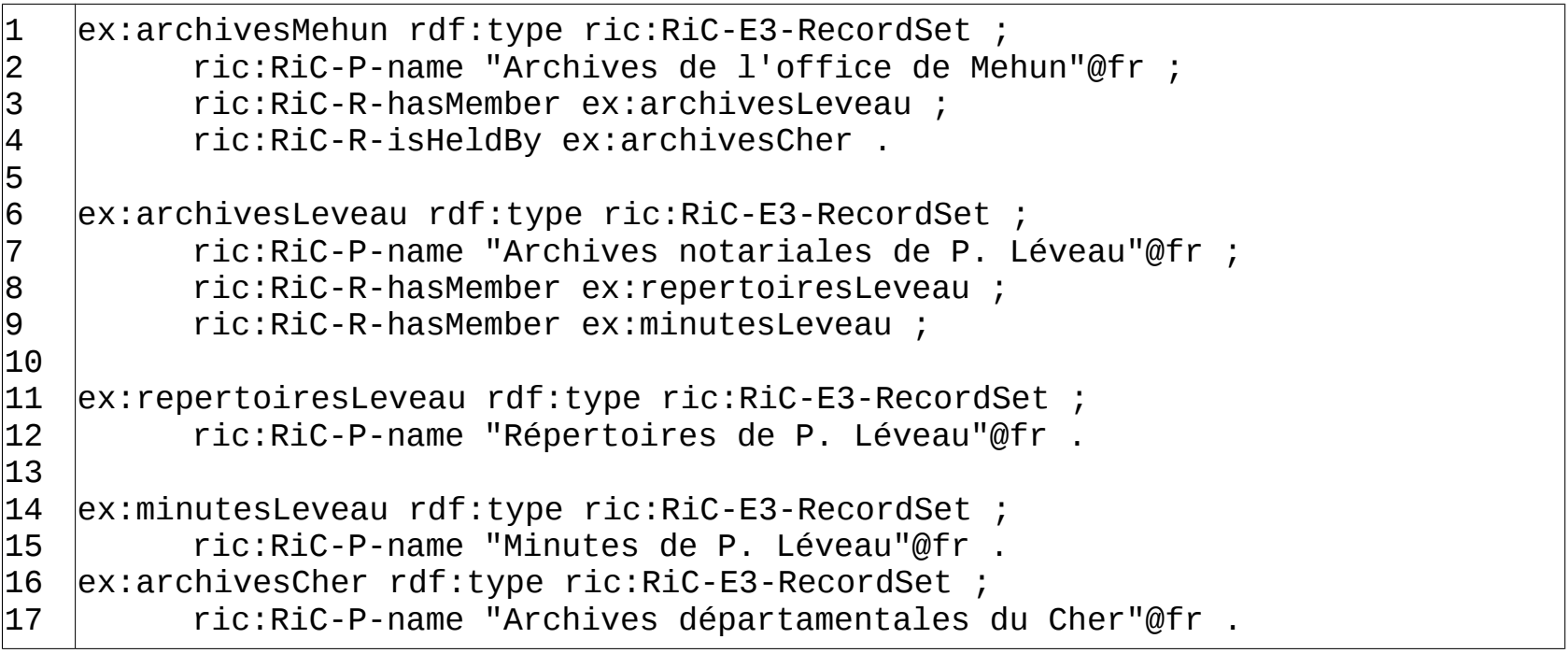

Dunia Llanes-Padrón, Juan-Antonio Pastor-Sánchez, (2017) "Records in contexts: the road of archives to semantic interoperability", Program, Vol. 51 Issue: 4, pp.387-405, https://doi.org/10.1108/PROG-03-2017-0021 
Table 5. RDF representation in N3/Turtle format of the example in the Figure 5. Source: Own.

One interesting aspect has to do with the use of the "RiC-P68 Date" and "RiC-P69 Place" properties, modeled in the ontology using the ric:RiC-P-date and ric:RiC-P-place annotation properties, respectively. These properties represent information about the relations between entities, i.e., descriptions on descriptions. RDF has a reification mechanism to define RDF sentences on other RDF sentences. This is seen in lines 47-52 and 60-65 in the Table 5, where the sphere of the ric:RiC-P-date relation established between people is indicated (ex:ejLeveau y ex:pgfLeveau) as well as the position (ex: premierechargeNotaire), as shown in the example.

\section{Conclusions}

Archival description is in a state of transition today and, like all change processes, it needs time and practice to be compared and to adapt information systems to the RiC-CM proposal. While based on the four international standards, this model goes beyond them both conceptually and structurally. $\mathrm{RiC}$ offers a structural and semantic modeling that facilitates the development of semantic and graphic technologies.

Records in Contexts is an opportunity to adopt new approaches for representing, accessing, publishing and reusing archival information in a web context. The preparation of this conceptual model represents a challenge for the archival world where there is need to create information systems that better face the challenge of creating, maintaining, managing and preserving archive information.

The publication of archival datasets is a valuable contribution within the LOD universe, as these datasets can be hugely enriched thanks to definitions of the links through controlled SKOS vocabularies, DBpedia entities, bibliographical records or any other type of RDF resource.

Once EGAD has finished its work and the ICA has published the definitive versions of the conceptual model and the ontology, the moment will be ripe to for the management and archival description tools to adapt to the proposal. Only the future will tell what repercussions Records in Contexts will have on web publication of archival data.

From now on the archival world will be well positioned to publish reliable, accessible and reusable datasets with resources that manage and preserve them over the long term. Published archival data, like LOD, will become easy to consult, to broaden and to reuse.

The final publication of Records in Contexts supposes a new challenge to Information Sciences as it moves towards the creation of a single conceptual model for the description of information resources. More and more theoretical and practical lines are being opened up which separate out the work procedures in archives, libraries, museums and other cultural institutions. There is no doubt 
that conceptual models, ontologies and formats are the way forward to compatibility and total interoperability of heritage and cultural information in the context of the semantic web.

\section{Glossary of abbreviations}

AGRkMS

ARANOR

CIDOC

CIDOC-CRM

CNEDA

DACS

EAC-CPF

EAD

EGAD

FRBR

GLAM

HTML

HTTP

ICA

ICOM

IGAD

IRI

ISAAR(CPF)

\section{$\operatorname{ISAD}(\mathrm{G})$}

ISDF

ISDIAH

ISO

JSON-LD

LOD

MAD3

MARC

MDM

N3

NEDA-I

NEPAN

NOBRADE

NODAC

NOGADA

NUDA

ODA

OWL
Australian Government Recordkeeping Metadata Standard.

Norma Aragonesa para la Descripción de Autoridades.

International Committee for Documentation (CIDOC) of the International Council of Museums (ICOM).

CIDOC-Conceptual Reference Model.

Comisión de Normas Españolas de Descripción Archivística.

Describing Archives: A Content Standards.

Encoded Archival Context-Corporate Bodies, Persons And Families.

Encoded Archival Description.

Expert Group on Archival Description.

Functional Requirements for Bibliographic Records

Galleries, Libraries, Archives and Museums.

Hypertext Markup Language.

Hypertext Transfer Protocol.

International Council on Archives.

International Council of Museums.

Irish Guidelines for Archival Decription.

Internationalized Resource Identifier.

International Standard Archival Authority Record For Corporate Bodies, Persons and Families.

General International Standard Archival Description.

International Standard for Describing Functions.

International Standard for Describing Institutions with Archival Holdings.

International Organization for Standardization.

JavaScript Object Notation for Linked Data.

Linked Open Data.

Manual of Archival Description.

MAchine-Readable Cataloging.

Manual de Descripción Multinivel.

Notation 3.

Norma Española de Descripción Archivística - Borrador.

Norma para la Elaboración de Puntos de Acceso Normalizados.

Norma Brasileira de Descrição Arquivística.

Norma de Descripción Archivística de Cataluña.

Norma Gallega de Descripción Archivística.

Norma Uruguaya de Descripción Archivística.

Orientações para a Descrição Arquivística.

Web Ontology Language. 
RAD2

RCPPN

RDA

$\mathrm{RDF}$

$\mathrm{RDFa}$

RDFS

$\mathrm{RiC}-\mathrm{CM}$

RiC-O

SPARQL

Turtle

URI

URL

XML

Z39.50

Rules for Archival Description.

Rules for the Construction of Personal, Place and Corporate Names.

Resource Description and Access.

Resource Description Framework.

Resource Description Framework in Attributes.

Resource Description Framework Schema.

Records in Context: a conceptual model for archival description.

Records in Context-Ontology.

SPARQL Protocol and RDF Query Language.

Terse RDF Triple Language.

Uniform Resource Identifier.

Uniform Resource Locator.

Extensible Markup Language.

Information Retrieval: Application Service Definition and Protocol Specification.

\section{Notes}

[1] The numbers of these entities in the conceptual model are: RiC-P23, RiC-P32, RiC-P42, RiCP45, RiC-P48, RiC-P52, RiC-P55, RiC-P58, RiC-P61, RiC-P63 and RiC-P66.

\section{References}

Acar, S., Alonso, J.M. and Novak, K. (2009), "Improving Access to Government through Better Use of the Web”, available at: https://www.w3.org/TR/egov-improving/\#interop (accessed 13 February 2017).

Baker, T., Bermès, E., Coyle, K., Dunsire, G., Isaac, A., Murray, P., Panzer, M., et al. (2011), "Library Linked Data Incubator Group Final Report", available at: https://www.w3.org/2005/Incubator/lld/XGR-lld-20111025/ (accessed 13 February 2017).

Bray, T., Paoli, J., Sperberg-McQueen, C.M., Maler, E. and Yergeau, F. (2008), “Extensible Markup Language (XML) 1.0 (Fifth Edition)”, available at: http://www.w3.org/TR/2008/REC-xml20081126/ (accessed 13 February 2017).

Brickley, D. and Guha, R.V. (2014), “RDF Schema 1.1”, available at: https://www.w3.org/TR/2014/REC-rdf-schema-20140225/ (accessed 13 February 2017).

Ciccarese, P. and Peroni, S. (2011), “Essential FRBR in OWL2 DL”, available at: http://purl.org/spar/frbr.

Comisión de Normas Españolas de Descripción Archivística. (2012), Modelo Conceptual de Descripción Archivística Y Requisitos de Datos Básicos de Las Descripciones de Documentos de Archivo, Agentes Y Funciones., Ministerio de Educación, Cultura y Deporte, Madrid, available at: http://www.mecd.gob.es/dms/mecd/cultura-mecd/areascultura/archivos/mc/cneda/documentacion/NEDA MCDA P1 P2 20120618pdf/NEDA MCDA P1 P2 20120618.pdf (accessed 16 February 2017). 
Cyganiak, R., Wood, D. and Lanthaler, M. (2014), “RDF 1.1 Concepts and Abstract Syntax”, available at: https://www.w3.org/TR/2014/REC-rdf11-concepts-20140225/ (accessed 13 February 2017).

Day, M. (2003), "Integrating metadata schema registries with digital preservation systems to support interoperability: a proposal”, Proceedings of International Conference on Dublin Core and Metadata Applications DC-2003 in Seatle, 27 Sept-2 Oct, available at:

http://dcpapers.dublincore.org/pubs/article/viewFile/728/724 (accessed 13 February 2017).

Gueguen, G., Fonseca, V.M.M. da, Pitti, D.V. and Sibille-de Grimoüard, C. (2013), “Hacia un Modelo Conceptual Internacional de Descripción Archivística: Un informe preliminar del Grupo de Expertos en Descripción Archivística del Consejo Internacional de Archivos”, Métodos de información, Vol. 4 No. 7, pp. 155-172.

Hernández-Pérez, T., Rodríguez-Mateos, D., Martín-Galán, B. and García-Moreno, M.A. (2009), "El uso de metadatos en la administración electrónica española: los retos de la interoperabilidad", Revista española de Documentación Científica, Vol. 32 No. 4, pp. 67-91.

Hidalgo-Delgado, Y., Senso, J.A., Leiva-Mederos, A. and Hípola, P. (2016), “Gestión de fondos de archivos con datos enlazados y consultas federadas”, Revista española de Documentación Científica, Vol. 39 No. 3, p. 145.

Hillmann, D., Coyle, K., Phipps, J. and Dunsire, G. (2010), "RDA Vocabularies: Process, Outcome, Use”, D-Lib Magazine, Vol. 16 No. 1/2, available at:https://doi.org/10.1045/january2010-hillmann.

International Council on Archives (ICA). (1992), "Statement of Principles Regarding Archival Description”, Archivaria, No. 34, available at: http://archivaria.ca/archivar/index.php/archivaria/article/view/11837/12789 (accessed 17 February 2017).

International Council on Archives (ICA). (2000), ISAD(G): General International Standard Archival Description, International Council on Archives, Ottawa, available at: http://www.ica.org/sites/default/files/CBPS 2000 Guidelines ISAD\%28G\%29 Secondedition EN.pdf (accessed 16 February 2017).

International Council on Archives (ICA). (2016), "Records in Contexts: A conceptual model for archival description (Consultation Draft v0.1)", available at: http://www.ica.org/sites/default/files/RiC-CM-0.1.pdf (accessed 13 February 2017).

International Organization for Standardization. (2016), ISO 15489 -- 1: Records Management -Concepts and Principles, ISO, Geneva.

Llanes Padrón, D. (2016), La Descripción Archivística En Los Tiempos Posmodernos: Conceptos, Principios Y Normas, Cultura Acadêmica, Marília: Oficina Universitária ; São Paulo, available at: (accessed 16 February 2017).

Marcondes, C.H. (2016), "Interoperabilidade entre acervos digitais de arquivos, bibliotecas e museus: potencialidades das tecnologias de dados abertos interligados”, Perspectivas Em Ciência Da Informação, Vol. 21 No. 2, pp. 61-83.

McKenna, G. (2013), “Linked Heritage Experience in Linking Heritage Information”, JLIS.it, Vol. 4 No. 1, p. 325-363. 
Moyano Collado, J. (2013), "La descripción archivística. De los instrumentos de descripción hacia la web semántica.”, Anales de Documentación, Vol. 16 No. 2, available at:https://doi.org/10.6018/analesdoc.16.2.171841.

Obrst, L. (2003), “Ontologies for Semantically Interoperable Systems”, Proceedings of the Twelfth International Conference on Information and Knowledge Management, ACM, New York, NY, USA, pp. 366-369.

Reinhardt, S. (2009), “CIDOC CRM in OWL 2”, available at: http://bloody-byte.net/rdf/cidoc-crm/ (accessed 13 February 2017).

Schneider, M. (2012), “OWL 2 Web Ontology Language RDF-Based Semantics (Second Edition)”, available at: https://www.w3.org/TR/2012/REC-owl2-rdf-based-semantics-20121211/ (accessed 13 February 2017).

Sheth, A., Arpinar, I.B. and Kashyap, V. (2004), "Relationships at the Heart of Semantic Web: Modeling, Discovering, and Exploiting Complex Semantic Relationships”, in Nikravesh, P.M., Azvine, D.B., Yager, P.R. and Zadeh, P.D.L.A. (Eds.), Enhancing the Power of the Internet, Springer Berlin Heidelberg, pp. 63-94.

Sheth, A.P. (1999), "Changing focus on interoperability in information systems: from system, syntax, structure to semantics”, in Goodchild, M., Egenhofer, M.J., Fegeas, R. and Kottman, C. (Eds.), Interoperating Geographic Information Systems, Kluwer Academic Publishers, Norwell, MA, USA, pp. 5-29.

Shotton, D. and Peroni, S. (2016), "FaBiO, the FRBR-aligned Bibliographic Ontology”, available at: http://purl.org/spar/fabio/.

Solodovnik, I. (2011), “Metadata issues in Digital Libraries: key concepts and perspectives”, JLIS.it, Vol. 2 No. 2, available at:https://doi.org/10.4403/jlis.it-4663.

Sulé, A., Centelles, M., Franganillo, J. and Gascón, J. (2016), “Aplicación del modelo de datos RDF en las colecciones digitales de bibliotecas, archivos y museos de España”, Revista española de Documentación Científica, Vol. 39 No. 1, p. 121.

Tolk, A. and Muguira, J.A. (2003), “The Levels of Conceptual Interoperability Model”, Fall Simulation Interoperability Workshop, Orlando, Florida, September 2003, available at: https://pdfs.semanticscholar.org/f655/af160f630b9be8dbab986f6a96953aa3e986.pdf (accessed 13 February 2017).

W3C OWL Working Group. (2012), “OWL 2 Web Ontology Language Document Overview (Second Edition)”, available at: https://www.w3.org/TR/2012/REC-owl2-overview-20121211/ (accessed 13 February 2017). 